\title{
Hydraulic Simulation of Waterbird Habitat Reconstruction
}

\author{
$W P$ Huang $^{1 *}, C Y \mathrm{Ku}^{2}, L K$ Chien $^{2}$, and $C J \mathrm{Ye}^{3}$ \\ 1 Associate Professor., National Taiwan Ocean University, Keelung, Taiwan \\ 2 Professor., National Taiwan Ocean University, Keelung, Taiwan \\ 3 Research Assistant, National Taiwan Ocean University, Keelung, Taiwan
}

\begin{abstract}
Cigu wetland consists of industrial salt ponds and lagoon is situated at the coast in the southwestern of Taiwan which is demarcated as Coastal Nature Reserve. The salt ponds experienced declines in bird species diversity and population compared with those within the lagoon area due to the deeper water depths. Different kinds of measures to alter water depths of salt ponds by filling soil are proposed. The hydrodynamic simulations were conducted for studying the hydrodynamic response to proposed reconstruction alternatives. The potential waterbird abundance was then estimated for the alternative recommendation. The methodology proposed in this study can reduce the risk of unexpected results by implementing the reconstruction project directly.
\end{abstract}

\section{Introduction}

The pressure on the coastal wetland is increasing with the threat of human exploitation (Burton et al.,1999; Timmermans et al., 2008)[1,2]. Ecological reconstruction is a necessary means to maintain the balance between development and nature in order to achieve the goal of sustainable use. It is the practice of reconstructing ecosystems which were degraded, damaged, or destroyed by anthropogenic action. However, ecosystems are extremely delicate, and improper human intervention may not be able to effectively maintain the expected improvements. Pre-assessment on the reconstruction project is thus vital to increase the effect and avoid negative impact (Barnes et al., 2007; Maleki et al., 2016)[3,4].

Cigu wetland is situated at the coast of Tainan City, a city in the southwestern of Taiwan which consists of Cigu lagoon and industrial salt ponds. The lagoon area is surrounded by alongshore barrier islands. On the other hand, the salt ponds are now obsolete and partly converted to fish ponds uses. Due to its richness in biodiversity, this area has been declared as Coastal Nature Reserve by the Construction and Planning Agency of the Ministry of the Interior, Taiwan. Located on the flyway for waterbird migration in Asia, tens of thousands of migratory birds will fly southwards passing this area; some even stay here for the winter. Almost 200 species of birds have been sighted. Among them, 21, including the endangered black-faced spoonbill (Platalea minor), are on the IUCN Red List (Huang and Yim, 2014)[5]. However, the salt ponds experienced declines in bird species diversity and population compared with those within the lagoon area. This is due to the suitability of the industrial salt ponds as the habitat for waterbirds is poor. Most of the depths within salt ponds are over $0.5 \mathrm{~m}$. The deeper water depths caused only the larger waterbird species, Anatidae were observed. Small species including Charadriidae and Scolopacidae are very few in this region because of lack of dry land and shallow water area. It should be possible to optimize the surroundings of the salt ponds to support a large number of waterbird species.

The waterbird communities are sensitive to hydrological change (Steen et al., 2006)[6]. Hydrological management thus becomes an efficient scheme for wetland restoration on waterbird population and stopover habitat. Jiang et al. (2016)[7] showed the wetland restoration project for Siberian crane stopovers by building causeway system to provide continuous water supplementation and maintain a suitable water level. The South Bay Salt Pond Restoration Project is the largest tidal wetland restoration project on the West Coast in the US. The project use kinds of water control structures including levees, channels, pumping, and water gates to restore and enhance a mix of wetlands habitat, also provide for flood management. These studies pointed out that to maintain a depth range that suitable for clusters of waterbirds and the water quality in wetlands are essential elements in promoting the rehabilitation of waterbirds. The measure to alter water depths of salt ponds is a feasible option for Cigu salt ponds. In addition, to enhance the ability of seawater exchange, water gates are suggested to open except typhoon invaded periods.

This study is a feasibility assessment to understand the waterbird abundance and hydrodynamic response to proposed reconstruction alternatives. To accomplish this objective, the bathymetric survey was carried out to understand the water depth range of observed waterbirds clustering. Then, the approach adopted was to develop a 
hydrodynamic model for this tidally influenced and hydrologically complex area to better understand the system.

\section{Methodology}

In Figure 1, the left panel shows the geographic location and the right panel is the water depth distribution of Cigu wetland. The lagoon area kept in a natural condition that has the variety of landscapes including sand dunes on barrier islands, tidal inlet, and marsh. The high and low undulating terrain accompanied by the calm water area bred the excellent habitat for flora and fauna as well as the waterbirds clustering discussed in this study. However, the salt ponds as the habitat for waterbirds are increasingly degraded. This is due to the landscape of salt ponds are monotonous without shelter vegetation that covered with water have a depth ranging from $0.5 \mathrm{~m}$ to $1.5 \mathrm{~m}$. Water depth exploited by different species at foraging sites often correlate with neck and tarsus length (Holm and Clausen, 2006)[8]. Consequently, within the water depth range, food is only available to larger species. Furthermore, seawater exchange is inefficient because the water gates are neglected. In order to improve both water quality and waterbird diversity in the industrial salt ponds, habitat reconstruction is prior work. The reconstruction alternatives in this study were designed with the intent of modifying the hydraulic behavior of the industrial salt ponds such that altering the water depth, and more water would be diverted from the sea.
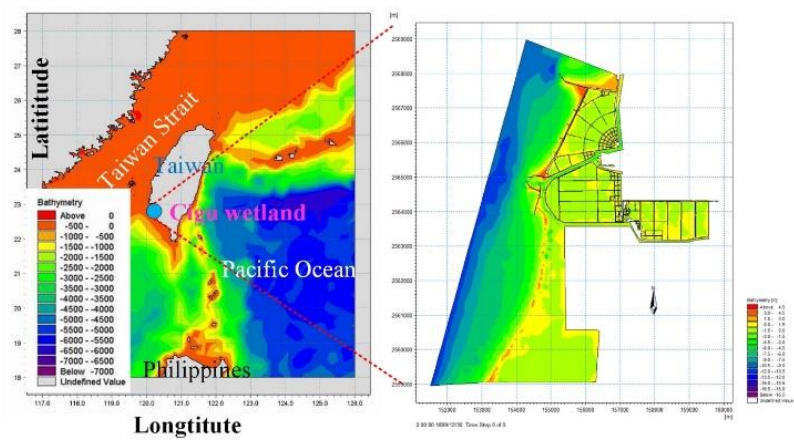

Fig. 1. The geographic locations and water depths of the study area.

Soil filling alternatives in Cigu industrial salt ponds is proposed to decrease water depths. However, it is too risky to conduct the field experiments directly. It may result in unexpected degradation due to the water circulation and the variations of the water depths within the area are unknown. The bathymetric survey of the wetland was thus carried out. The data were used for two purposes: (1) understand the water depth range of observed waterbirds clustering and (2) construct a numerical simulation model.

Numerical simulation is a cost-effective and timesaving method to study the existing condition and also to evaluate the effects of proposed alternatives. The twodimensional numerical model MIKE 21 developed by DHI was used to study hydrodynamics. The model employs unstructured, non-uniform, triangular meshes with arbitrarily spatially dependent, which enables the computation grid to fit the variable bathymetry of the study site. The variations of water levels, depths, and current speeds induced by the tidal flow can be estimated. The effects of wave mechanisms are neglected in the simulations since the wetlands are protected by sandbars and breakwaters that their hydrological characteristics are dominated by tides not by waves. The total duration of the simulations is 28 days, including the spring and neap tides of the entire tidal month. The hydrological characteristics within the wetland can be fully studied.

The abundance refers to water depth can be regarded as the index to assess alternatives. Table 1 shows the abundance of different waterbird species at different water depths that investigated within the Cigu lagoon area adjacent to salt ponds. Water depths less than $30 \mathrm{~cm}$ have larger values of the abundance. It should be noted that the water depths are not a constant in the spatial and temporal domain which varied with the tidal flow, channels, water gates, and bathymetry. The hydraulic simulations can offer the percentage of time refer to the different ranges of water depth. The product of the time percentage and the abundance can be used for the evaluation of alternatives.

Table 1. The abundance of different waterbird species at different water depths.

\begin{tabular}{lcc}
\hline \multicolumn{1}{c}{ Species } & Water depth $(\mathrm{m})$ & Abundance \\
\hline Charadriidae & $0 \sim 10$ & 51 \\
Scolopacidae & $0 \sim 20$ & 69 \\
Nipponia nppon & $0 \sim 30$ & 190 \\
Duck & $30 \sim 100$ & 52 \\
\hline
\end{tabular}

\section{Results}

The model was applied to simulate the hydrodynamics for the existing condition and reconstruction alternatives. Time series of tidal water surface elevation measured by Jiang-Jun fishery harbor that located at the seaward side of Cigu salt pond was used to parameters calibration firstly. Adjusting bottom roughness and refining simulation meshes were conducted. After the calibration, the relative errors between the measured and calculated tidal elevations at each time step were less than $5 \%$.

Figure 2 shows the variations of the water depth at some of the salt ponds extracted from the twodimensional hydrodynamic simulations under the existing condition when all water gates are open. The variations of water depth are determined based on the bathymetry, causeways, and the opening elevations of the gates. The depths of adjacent evaporation pools thus shown different characteristics. For example, the No. 6 and No.8 ponds are the inlet sink which has the same variation amplitudes of water level elevations compare with the open sea. As for the evaporation pools, from No. 10 to No. 19, the variations of the water depths decrease with the increasing distance away from the inlet channel. Thus No. 10 to No.19 ponds are selected to assess the feasibility of filling soil due to the amplitude of the water depth variation is rather small. 


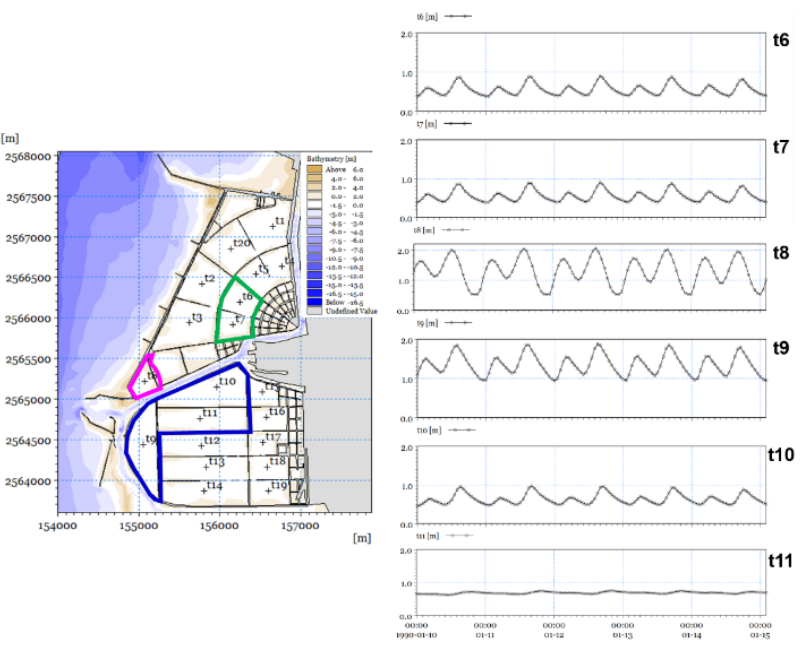

Fig. 2. The variations of the water depth at the salt ponds.

There are 3 reconstruction alternative plans proposed. Two of them were designed for large salt ponds and the last one was set for small evaporation pools. The profiles of the 3 setups are shown in figure 3 . Alternative 1 is to fill soil into the whole salt ponds until the elevation reaches $0.1 \mathrm{~m}$. Alternative 2 includes creating a shallow water area with a mild slope and a plane zone. Alternative 3 is a kind of duplex profiles including deep water, shallow water, and dry lands that suitable to implement in a rather small area. The former two alternatives were designed for No. 11 No. 14 salt ponds. The last one which was much more complex that was set for No. 16 No. 19 evaporation pools.
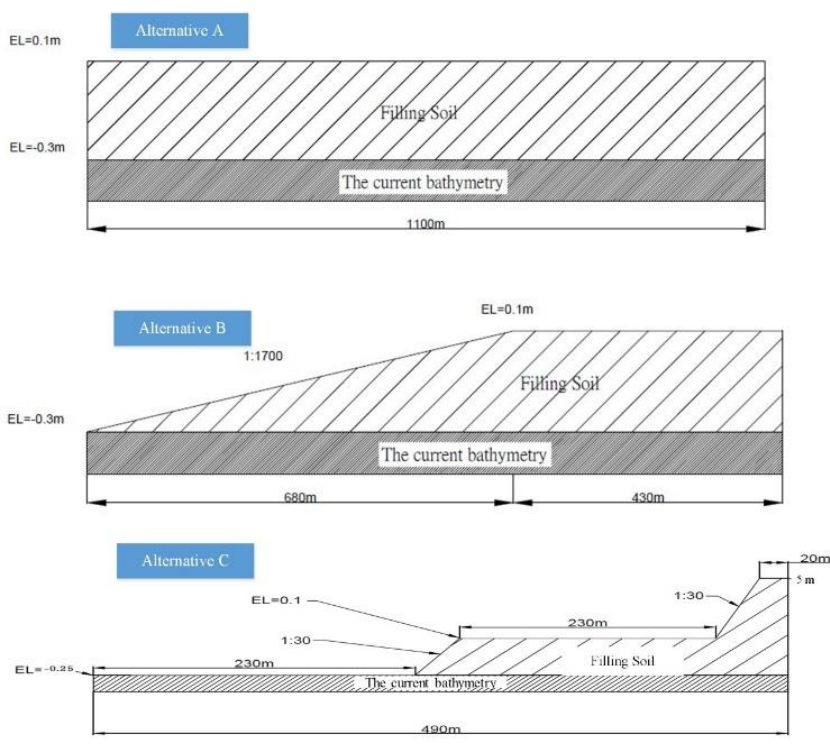

Fig. 3. The profiles of 3 soil filling alternatives.

Three reconstruction alternatives under the same tidal variation boundaries were simulated for comparison. The time series of the variations of water depth at each sampling points can be categorized into the different ranges of water depth including $0 \sim 10 \mathrm{~cm}, 10 \sim 20 \mathrm{~cm}$, $20 \sim 30 \mathrm{~cm}$, and above than $30 \mathrm{~cm}$. The percentage times in the different ranges of water depth during the entire 28 - day tidal month can be then estimated. The product of the percentage times the bird abundance can be used as comparing the effectiveness of each reconstruction alternative.

Figure 4 shows the abundance score bar charts of the existing condition and 3 alternatives at sampling spots respectively. The scores of the existing condition are the bar charts in blue and those of the reconstruction alternatives are in red. With decreasing in water depths by filling soil, the abundance scores increased in all of the 3 alternatives. Alternative 1 would yield similar abundance scores in the whole area since the elevation of filling soil is the same. Both alternative 2 and 3 were designed with a mild slope for increasing natural diversity and reducing the volumes of filling soil. However, the increasing scores in the slope area are lower than those in the plane area.

It should be noted that the alternative recommendations cannot be determined by the abundance scores since they are spatially dependent and the areas of the alternative implementation are not the same (the upper panel of figure 4). The volumes of filling soil are proportional to the project budget. On the other hand, the summation of increasing abundance score at each grid can be regarded as the effectiveness of the alternative. The ratio of the summation score to the volumes can be regarded as the unit benefit of the investments. Then, the alternative can be recommended by comparing the ratios. Alternative 1 appeared to provide the most benefit relative to the costs that shown in figure 4 . Alternative 2 and 3 have almost the same performance in enhancing the waterbird abundance.

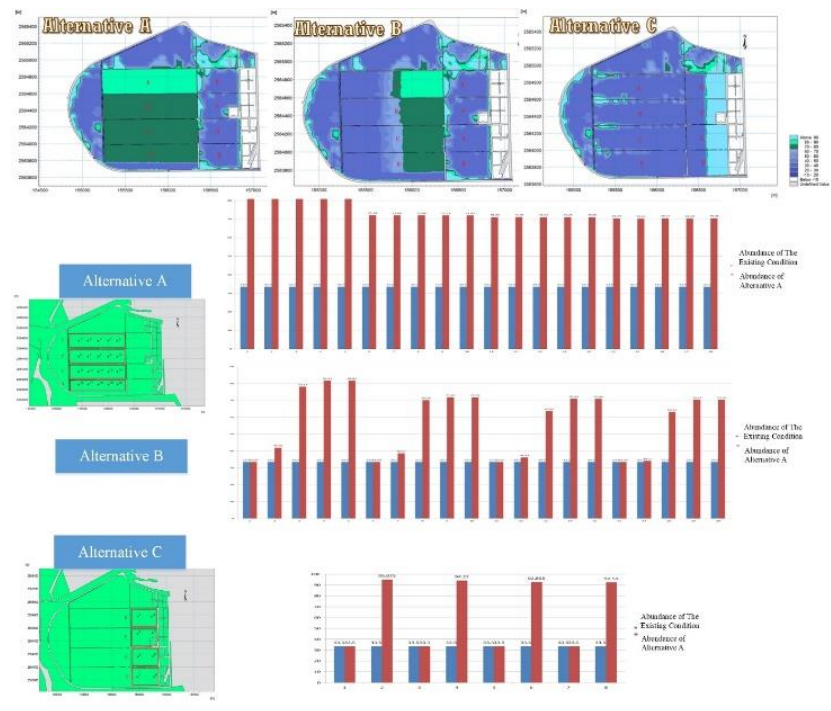

Fig. 4. The abundance scores of the existing condition and 3 alternatives.

\section{Conclusions}

Wetland reconstruction projects are necessary to increase the waterbird abundance in Cigu wetland. The water depth appears to be the significant factor in enhancing the waterbird abundance due to the foraging behaviors. In this study, a hydrodynamic model was used to study the 
tidally influenced and hydrologically complex area. The model was validated with observed data collected from the neighboring fishery harbor and applied to evaluate 3 designed reconstruction alternatives to improve the suitability of the habitat for waterbirds. The unit benefit of the investments in terms of the ratio of the increasing abundance to the filling soil volumes is proposed in this study for alternatives selection. Alternative 3 provides more benefits in terms of restoration cost.

The ecosystems are extremely delicate and they don't work as logically as math. That is the reason that some reconstruction alternatives may not perform up to expectations. Admittedly, the more rigorous simulations can reduce the risk of failure. The methodology proposed in this study links the physical hydrodynamic simulations and field survey data, waterbird abundance that provide a reasonable method to choose the reconstruction alternative. The estimate can be used for a field experiment in the future.

\section{Acknowledgments}

This paper is partly aided by a project of the Ministry of Science and Technology, Republic of China, Project no. MOST 106-2621-M-019-003-MY2. Their support is deeply appreciated.

\section{Reference}

1. Burton, T.M., Uzarski, D.G., Gathman, J.P., Genet, J.A., Keas, B.E., and Stricker, C.A. Development of a preliminary invertebrate index of biotic integrity for Lake Huron coastal wetlands. Wetlands 19:869-882, (1999).

2. Timmermans S.TJ., Badzinski S.S. and Ingram J. W., "Associations between Breeding Marsh Bird Abundances and Great Lakes Hydrology", J. Great Lakes Res., Vol. 34, pp351-364, (2008).

3. Barnes, T. K., et al. "A habitat suitability index model for the eastern oyster (Crassostrea virginica), a tool for restoration of the Caloosahatchee Estuary, Florida." Journal of Shellfish Research 26.4: 949-959, (2007).

4. Maleki, Saeideh, et al. "Habitat mapping as a tool for water birds conservation planning in an arid zone wetland: The case study Hamun wetland." Ecological Engineering 95: 594-603, (2016).

5. Huang, Wei Po, and John Z. Yim. "Sand dune restoration experiments at Bei-Men coast, Taiwan." Ecological Engineering 73: 409-420, (2014).

6. Steen D.A., Gibbs J.B. and Timmermans S.TJ., "Assessing the sensitivity of wetland bird communities to hydrologic change in the eastern great lakes region", Wetlands, Vol. 26, No. 2, pp 605-611, (2006).
7. Jiang, Haibo, et al. "The effects of a wetland restoration project on the Siberian crane (Grus leucogeranus) population and stopover habitat in Momoge National Nature Reserve, China." Ecological Engineering 96: 170-177, (2016).

8. Holm, Thomas Eske, and Preben Clausen. "Effects of water level management on autumn staging waterbird and macrophyte diversity in three Danish coastal lagoons." Biodiversity \& Conservation 15.14: 43994423, (2006). 